\title{
Clonazepam Measurement
}

National Cancer Institute

\section{Source}

National Cancer Institute. Clonazepam Measurement. NCI Thesaurus. Code C139082.

The determination of the amount of clonazepam present in a sample. 